\title{
AGENDA PENDIENTE SOBRE LOS AMICI CURIAE. ANÁLISIS A LA LUZ DE LOS DERECHOS FUNDAMENTALES
}

Open agenda about the concept AMICE CURIAE. Analysis taking into account the fundamental rights.

Jorge Isaac Torres Manrique ${ }^{1}$

Recibido: 02 de septiembre 2019 - Aceptado: 15 de diciembre de 2019

\section{RESUMEN}

La institución jurídica del amicus curiae no presenta reconocimiento legal ni constitucional, en muchos países. Consecuentemente, su desarrollo y su utilización no son los esperados. En el presente trabajo se aborda dicha temática, para fijar el alcance y los fines de esa figura jurídica. Ello, en razón a su capital influencia en la participación ciudadana en el poder judicial, así como en la legitimidad que le otorga a la judicatura. Por otro lado, abordamos la relación existente entre el amici y los derechos fundamentales, así como, la determinación de los irrestrictos derechos fundamentales involucrados.

Palabras clave: Amicus curiae; amigo del tribunal; derechos fundamentales.

\begin{abstract}
The legal institution of the amicus curiae does not present legal or constitutional recognition, in many countries. Consequently, its development and use are not as expected.This topic is addressed in the present work, to establish the scope and purposes of this legal figure. This, due to its capital influence on citizen participation in the judiciary, as well as the legitimacy it grants to the judiciary. On the other hand, we address the relationship between amici and fundamental rights, as well as the determination of the unrestricted fundamental rights involved.
\end{abstract}

Keywords: Amicus curiae; friend of the judge; fundamental rights.

${ }^{1}$ Consultor jurídico. Abogado por la UCSM (Arequipa). Doctorados en Derecho y Administración, por la UNFV (Lima). Par Académico Evaluador de las firmas editoras: Corporación de Estudios y Publicaciones (Ecuador) y Ediciones Jurídicas de Santiago (Chile). Miembro de la International Association of Constitutional Law- IACL (Serbia). https://orcid.org/0000-00015202-3886 E-mail: kimblellmen@ outlook.com 


\section{PROLEGÓMENO.}

Desde hace más de una década se discute en torno a los problemas de imagen y legitimidad que afectan a gran parte de los poderes judiciales de América Latina. En muchos países de la región -y esto no resulta novedoso- las encuestas indican, de manera sostenida, que los niveles de confianza de la ciudadanía en el Sistema de justicia son preocupantemente bajos. Las causas detrás de este diagnóstico son múltiples: falta de independencia de los jueces, obstáculos para el acceso a la justicia, ineficacia del poder judicial para hacer frente a la inseguridad ciudadana y casos de corrupción judicial, entre otras. (Herrero, 2008).

El Estado democrático de derecho tiene como principal fundamento la participación popular en la toma de decisiones del poder público. A través del diálogo con los distintos grupos sociales, el Estado puede adecuar sus medidas y tornarlas más próximas a sus necesidades y aspiraciones reales. De esta forma, instituir mecanismos que fomenten dicha comunicación y que funcionen como un puente de diálogo entre la sociedad civil y el Estado es indispensable para el pleno funcionamiento democrático. (Bauer, 2016).

Es debido a lo señalado, que en la presente entrega analizamos la importante institución jurídica como es el amicus curiae. Ello, en razón a su capital influencia en la participación ciudadana en el poder judicial, como en la legitimidad que le otorga a la judicatura.

Por otro lado, abordamos la relación existente entre el amici y los derechos fundamentales, así como, la determinación de los irrestrictos derechos fundamentales involucrados.

Finalmente, desarrollamos los puntos que consideramos pendientes de resolución, a efectos de viabilizar su efectiva como saludable participación.

\section{ACERCA DEL AMICI CURIAE.}

En principio, es de señalar que resulta innegable la saludable presencia del amici curiae, conocido también como: amicus curiae, amigo del tribunal, amigo de la corte, asistente oficioso; y que denominaremos: tercero coadyuvante. Ello es de corroborar igualmente en sede interna estatal, como en la jurisdicción internacional, llámese Corte Interamericana sobre Derechos Humanos, por ejemplo.

El término amicus curiae, reminiscencia del derecho romano clásico, es traducido en la actualidad como amigo de la corte y refiere mínimamente a participaciones orales o escritas de personas o instituciones que no son parte formal de un juicio, ni demandantes ni demandados. El canon dicta que la justicia debe ser independiente si se atiende a su misma representación latina con los ojos vendados, en cada caso ha de ponderar solamente las pruebas y argumentos aportados por las partes del juicio. (González y Sotelo, 2019). 
Jorge Isaac Torres Manrique

De hecho, dada su naturaleza peculiar, es diferente de las otras especies, puesto que su función es ayudar en cuestiones técnicas y jurídicas, proporcionando al juez con elementos para la aplicación de la ley sea eficaz y eficiente. No hay que confundir la figura del "amicus curiae" con el experto, puesto que ese actúa en asistencia al magistrado en cuestión de pruebas periciales. El "amicus curiae" trabaja sobre la cuestión de la interpretación en el mundo hermenéutico. (Costa de Santana, 2014).

Las presentaciones del amicus curiae, no requieren necesariamente ser de carácter legal, pudiendo ofrecer otras perspectivas (histórica, económica, sociológica, etc.), no obstante, de tener alguna incidencia jurídica, ayudando en la investigación y aportando datos y presunciones; todo lo cual denota la amplitud en que se desenvuelve la actividad propia a esta figura. Por otra parte, la interposición de amicus curiae publicita los argumentos empleados frente a una cuestión de interés general decidida por el Poder Judicial, identificando claramente la posición de los grupos interesados y sometiendo a la consideración general las razones que el Tribunal tendrá presente al adoptar y fundar su decisión; por todo lo cual, esta figura posibilita ampliar la argumentación de una posición, convirtiéndose en un mecanismo de novedosa participación ciudadana. (Baquerizo, 2006).

Estados Unidos de Norteamérica, por ejemplo, es uno de los países con mayor utilización de esta figura, especialmente a nivel de los tribunales federales en el control constitucional difuso propio de esta jurisdicción. Su dimensión es tal que han asumido roles protagónicos ante la propia Corte Suprema de ese país en numerosas ocasiones. (Baquerizo, 2006).

Cabe señalar, que tanto las personas naturales, las morales, así como, las instituciones estatales, podrán intervenir como amici curiae. Ello le otorga una naturaleza de completitud, esto es, que posibilita intervención de la totalidad de miembros de la ciudadanía. Así concuerda con la calidad que abraza, es decir, de interés público.

La sujeción a la neutralidad por parte del amicus curiae, otrora exigida, ha sido invertida en la época actual; lo único que se espera de aquél es una inteligente contribución sobre la problemática inmersa en la causa, sabiendo de antemano que el 'amicus' es más amigo de aquella que del propio Tribunal. (Baquerizo, 2006).

El amicus curiae se muestra como un claro mecanismo que permite no sólo la ampliación de participantes en el debate procesal sino también la mayor legitimidad funcional de la potestad jurisdiccional ejercitada por el juzgador. Consecuentemente, mientras en mayor grado se aprecie la participación de ideas en la controversia sometida a la decisión racional del juez, creemos que mayor será la legitimidad del fallo (o incluso del prece-dente) que se emane, cumpliendo más que suficientemente el funda-mento democrático del Poder 
Judicial. Las piezas del Derecho que el juez tendrá a su disposición para fundar su decisión, no serán monotemáticas sino variadas, no estarán ancladas en el pasado sino al corriente de las últimas corrientes jurídicas y, en adición, dotarán a su labor de una legitimación adicional, justamente por haber permitido que el radio del proceso se haya extendido hacia otros sectores interesados y comprometidos de la comunidad. (Baquerizo, 2006).

Se hace presente que el tercero (amicus curiae) presenta voluntariamente el escrito, esto es, no es compelido por nadie ni nadie tiene el poder de compelerlo. El escrito se presenta porque el tercero así quiere hacerlo, porque quiere defender un interés legítimo en un juicio donde se discute un asunto de interés colectivo o público. De todas formas, es posible admitir que el tribunal puede hacer un llamado a presentar escritos por parte de amici curiae, pero dicha facultad no representa el surgimiento de una obligación o carga procesal sobre el tercero, quien más bien ha sido invitado a ejercer dicho papel. (Hidalgo, 2017).

Por otro lado de verse, que el Art. 13-A.-, del Reglamento Normativo del Tribunal Constitucional peruano, establece como facultad especial que: "El Pleno o las Salas pueden solicitar los informes que estimen necesarios a los órganos de Gobierno y de la Administración y requerir respuesta oportuna de ellos, de acuerdo al artículo 119 del Código Procesal Constitucional; así como solicitar información del (los) amicus curiae (amici curiarum), si fuera el caso, que permita esclarecer aspectos especializados que puedan surgir del estudio de los actuados".

A su turno, tenemos que el Inc. 20., del Art. 2.- de la Constitución Política peruana, acerca de los derechos fundamentales de la persona, preconiza: "Toda persona tiene derecho: A formular peticiones, individual o colectivamente, por escrito ante la autoridad competente, la que está obligada a dar al interesado una respuesta también por escrito dentro del plazo legal, bajo responsabilidad".

Luego, el Art. 44., de la Convención Americana sobre Derechos Humanos, sobre la competencia, establece: "Cualquier persona o grupo de personas, o entidad no gubernamental legalmente reconocida en uno o más Estados miembros de la Organización, puede presentar a la Comisión peticiones que contengan denuncias o quejas de violación de esta Convención por un Estado parte".

Seguidamente, el Inc. 1., del Art. 48., de la referida Convención, en relación al procedimiento, registra: "La Comisión, al recibir una petición o comunicación en la que se alegue la violación de cualquiera de los derechos que consagra esta Convención, procederá en los siguientes términos: a) Si reconoce la admisibilidad de la petición o comunicación solicitará informaciones del Gobierno del Estado al cual pertenezca la 
Jorge Isaac Torres Manrique

autoridad señalada como responsable de la violación alegada, transcribiendo las partes pertinentes de la petición o comunicación. Dichas informaciones deben ser enviadas dentro de un plazo razonable, fijado por la Comisión al considerar las circunstancias de cada caso".

La intervención del amicus curiae posee dos justificaciones teóricas principales, además de aquellas ya expuestas a título introductorio. En primer lugar, es necesario admitir que los pocos magistrados del TC, aunque sean especialistas en las ciencias jurídicas, no pueden conocer plenamente todas las cuestiones debatidas en el ámbito de la justicia constitucional. De esa forma, nada más razonable que permitir que terceros, capaces de contribuir técnica o científicamente para solucionar la cuestión puesta en debate, puedan solicitar su ingreso. De esta manera, las decisiones tendrán unos mejores fundamentos y se contribuirá más satisfactoriamente al principio de la motivación y a la legitimación de estas. Además de esta cuestión, que por sí sola podría respaldar y justificar la participación procesal de la figura aquí estudiada, hay otra específicamente relacionada con la teoría de los intérpretes de la Constitución, largamente difundida por el constitucionalista Peter Häberle. (Bauer, 2016).

El amicus curiae, es un instrumento que permite a la sociedad civil organizada participar activamente en el proceso de resolución de juicios que conocen los impartidores de justicia, a través de la presentación de una opinión técnica en cualquier etapa procesal previa a la emisión de la sentencia. Es un medio de naturaleza jurídica que permite al tercero ajeno a juicio ocurrir ante el tribunal que resolverá algún litigio, exhibiendo una opinión técnica debidamente sustentada que resulte relevante para la resolución de dicho juicio, dada la trascendencia que este tendrá en la esfera social, política, jurídica o económica del país. El documento deberá ser elaborado y presentado por una persona que no tenga interés en la resolución del juicio. (Mendoza, 2019).

Al respecto cabe plantear: ¿Cómo podrían los jueces, pero sobre todo la sociedad en su conjunto a través de ellos, resolver los asuntos de una manera en que la democracia y los derechos humanos sean respetados y valorizados? Es innegable la ayuda que en dicho sentido puede ofrecer el diseño de instituciones o herramientas que actúen en el marco de la administración de justiciar. ¿No resultaría útil para la sociedad civil un instrumento procesal que permita ampliar el, debate judicial, y donde la misma pueda actuar de manera que enriquezca jurídicamente la discusión en su propio beneficio? Consideramos que la institución del amicus curiae podría contribuir al cumplimiento de dichos objetivos. (Martin, 2015).

El uso de esta institución tiene las siguientes virtudes: i) Genera una práctica de impartición de justicia más democrática y deliberativa, ii) Incentiva a los juzgadores a revisar los 
proyectos de sentencia con mayor ahínco, pues la opinión pública será más estricta al tener un documento como punto de comparación frente a las sentencias que emitan, iii) Aporta posiblemente elementos que no habían sido considerados por el juzgador, y iv) Legitima a los tribunales en la toma de decisiones. (Mendoza, 2019).

Así también, como ventajas de la presentación de un amicus curiae, tenemos: i) Asegura que el Poder Judicial esté en conocimiento de las implicancias del caso en el ámbito comunitario, ii) Asiste a las partes, iii) Beneficia el desarrollo jurisprudencial en ese campo, iv) Según algunos estudios, existe una relación positiva entre el número de amicus curiae y la decisión del Poder Judicial al fallar, v) Aporta argumentos legales a la causa, describiendo la forma en que puede afectar a personas que no son partes, vi) Brinda carácter público a los argumentos empleados frente a una cuestión de interés general decidida por el Poder Judicial, identificando claramente la posición de los grupos interesados, y sometiendo a la consideración general las razones que el tribunal tendrá presentes al adoptar y fundar su decisión. (Cesario, s/a).

Es por esta significativa utilidad que el uso de esta figura procesal (originada en el Derecho Romano y, modernamente, en la tradición jurídica anglosajona del siglo XIX) se ha extendido a la mayoría de sistemas jurídicos nacionales como el nuestro, y está siendo utilizado también, de modo sostenido, ante los órganos internacionales de protección de los derechos humanos (comisiones, cortes y tribunales internacionales), por lo que hoy en día no se pone en duda su importancia como un eficaz mecanismo para configurar un sistema judicial accesible, independiente y eficiente. (Castañeda, 2010).

El amicus curiae, como forma de intervención de la Defensoría del Pueblo, tiene fundamento normativo en el artículo 162 de la Constitución de 1993 y en el artículo 17 de la Ley N ${ }^{\circ}$ 26520, Ley Orgánica de la Defensoría del Pueblo. Su objetivo es aportar, como "amigo del tribunal", criterios técnico-jurídicos no vinculantes, útiles para una adecuada interpretación de los derechos fundamentales, con la finalidad de contribuir con la supremacía de la Constitución Política. (Adjuntía (e) en Asuntos Constitucionales de la Defensoría del Pueblo, 2009).

Los principios que dan sustento constitucional al amicus curiae son los siguientes: i) Participación ciudadana, principio democrático y transparencia del debate judicial, ii) Garantía del debido proceso, y iii) Garantía de la plena vigencia de los derechos humanos. (Adjuntía (e) en Asuntos Constitucionales de la Defensoría del Pueblo, 2009).

Esta forma de intervención es reconocida y aceptada por los órganos jurisdiccionales nacionales como el Tribunal Constitucional y el Poder Judicial, así como por instancias 
Jorge Isaac Torres Manrique

supranacionales como la Comisión Interamericana de Derechos Humanos (CIDH) y la Corte Interamericana de Derechos Humanos, pues se tiene en claro que no supone una injerencia indebida en la función jurisdiccional, sino que, por el contrario, constituye una muestra de cómo nuestro Sistema jurídico exige la colaboración interinstitucional de entidades como la Defensoría del Pueblo y los órganos jurisdiccionales, en la tarea común de garantizar la efectiva vigencia de los derechos fundamentales de todos los integrantes de la ciudadanía. (Adjuntía (e) en Asuntos Constitucionales de la Defensoría del Pueblo, 2009).

Sobre la oportunidad de la intervención, el documento del amicus curiae puede ser aportado una vez que se inicie el proceso judicial y antes de que se emita la sentencia definitiva. (Adjuntía (e) en Asuntos Constitucionales de la Defensoría del Pueblo, 2009).

La decisión sobre la admisibilidad de la intervención en calidad de amicus curiae le corresponde al tribunal que conoce el proceso en el cual se pretende intervenir. Dicha decisión no se sujeta al consentimiento o aquiescencia de las partes o terceros legitimados, como consecuencia del carácter ilustrativo y no vinculante de este tipo de intervención que, finalmente, no se opone a las pretensiones de los litigantes. Por consiguiente, su admisión "no requiere del consentimiento de las partes, dependiendo enteramente de que el Tribunal la considere conveniente". (Adjuntía (e) en Asuntos Constitucionales de la Defensoría del Pueblo, 2009).

Dentro de las particularidades del amici curiae, tenemos: i) están facultadas para comparecer como amici curiae las personas físicas o de existencia real y las personas jurídicas, morales o de existencia ideal (según las distintas nomenclaturas que puedan emplearse), siempre que acrediten reconocida competencia en la temática en examen en el proceso, ii) el amicus curiae no reviste carácter de parte ni mediatiza, desplaza o reemplaza a estas, iii) su intervención no debe confundirse con la de un perito o de un consultor técnico, iv) su actividad se ciñe a expresar una opinión fundada en defensa de un interés público o de una cuestión institucional relevante, por lo que, precisamente, debe ostentar un afán justificado en la decisión que pondrá fin al pleito en el que se presenta, debiendo aquel exceder el de los directamente afectados por la resolución concreta; y, por último, v) su comparendo no vincula al tribunal actuante ni genera costas u honorarios. (Bazán, 2014). El amicus curiae es un instrumento plausible y digno de ser explorado para tonificar el debate jurisdiccional constitucional -ampliando los márgenes de deliberación en cuestiones de trascendencia social por medio de argumentos públicamente analizados-, aportar a la defensa y la realización de los derechos humanos y contribuir a la elaboración de sentencias razonables y generadoras de un grado sustentable de consenso en la comunidad. (Bazán, 2014). 
Es de apostrofar, que el tercero coadyuvante no se encuentra legislado en sede legal, ni en la constitucional, lo que limita su accionar en beneficio de una mejor resolución de los procesos.

En ese sentido, la adopción de una disposición específica en torno a la referida figura que explicite los requisitos de legitimidad y los poderes procesales correspondientes - no solo reduciría la inseguridad jurídica de los postulantes en torno a su admisión en el proceso, sino que también contribuiría con su apertura -todavía restringido a un pequeño rol de legitimados- a distintos sectores de la sociedad, lo que tornaría más legítimas y democráticas las decisiones de un tribunal tan fundamental para un Estado de derecho. (Bauer, 2016).

Dentro de las funciones y fines de los amigos del tribunal, tenemos: i) El amicus racional y argumentativo y la decisión judicial correcta, y ii) La representación de intereses y el acceso a la justiciar. (Hidalgo, 2017).

Resulta de capital importancia traer a colación, que los amicus curiae pueden utilizarse bajo cinco roles (Sandoval, 2018):

i) Para ampliar o complementar los principales argumentos fácticos y jurídicos presentados brevemente en el escrito de una de las partes, proporcionando claridad al juzgador de manera a como lo hace la prueba testimonial. También puede presentar datos que no consten en el expediente los cuales ayudarán al juzgador a resolver el asunto de manera más informada. En este tipo de escrito es incluso deseable presentar los hechos de manera diferente a como lo hagan las partes, así como presentar circunstancias que éstas no hayan presentado.

ii) Puede estar enfocado en un argumento legal alternativo al provisto por las partes. Esto es particularmente importante si una de las partes, a consideración del amicus, "no está poniendo su mejor esfuerzo en su defensa legal", o bien cuando las partes no han invocado de manera correcta precedentes relevantes. Además, este estilo de escrito es apropiado para discutir puntos considerados demasiado particulares o extensos por las partes.

iii) Puede ser utilizado para hacer de conocimiento al juzgador sobre la amplia base de implicaciones legales, sociales y económicas que derivarán de determinado punto de la resolución, o bien sobre las consecuencias que la misma resolución podría acarrear para un determinado grupo que no comparece ante el juzgador. Esta es un rol importante, ya que provee de voz a aquellas personas que no son partes, pero podrían ser afectadas por la resolución. Generalmente, este tipo de escritos provee 
Jorge Isaac Torres Manrique

información que no consta en el expediente, usualmente en la forma de información científica especializada, para reforzar posturas.

iv) Puede proporcionar información que permita al juzgador basar su decisión en un marco legal más amplio, comprensible y preciso. Una forma de hacer esto es usar el escrito para informar al juzgador de otros litigios pendientes que serán influenciados por el resultado del asunto que él resuelve, e informarlo de las diferencias entre estos litigios, lo que puede requerir el refinamiento del análisis jurídico. Este estilo de escrito también sirve para instar a la Corte a regular sus decisiones, y proporcionar un análisis jurídico demostrando por qué se tomaría una mala decisión, y por consecuencia sería un mal precedente para futuros casos en situación similar. En segundo lugar, este tipo de escrito puede ofrecer una colección de referencias que merezcan una compilación judicial.

v)Finalmente, es apropiado el uso de estos escritos para describir las complejidades de un campo especializado, como puede ser el relativo a la protección de los menores, ante el juzgador. A menudo, quien redacta un escrito amicus suele estar más familiarizado con el tema que las partes, y es importante para el juzgador tener acceso a esta experiencia. También hay casos en que el amicus curiae puede estar más en una mejor posición que cualquiera de las partes para defender el punto de vista de éstas.

Por otro lado, es de precisar que el amicus curiae puede ser utilizado en cinco grandes momentos o fines: i) como argumentos necesarios para completar una aproximación de los magistrados a los hechos que se pretender analizar y evaluar en un caso concreto; ii) Como criterios legales a través de argumentaciones jurídicas que puedan servir de base para la resolución de conflictos; iii) Como eventuales especulaciones de eventuales resoluciones por parte de los magistrados, que puedan vulnerar los derechos de la colectividad; iv) Como marco legal amplio, compatible y preciso, a través de opiniones de expertos para la resolución de controversias que necesiten de información especializada; y, v) Finalmente, para otorgar especialidad a un campo poco estudiado y abierto de las ciencias jurídicas que necesite ser evaluado. (Sandoval, 2018).

\section{SOBRE LA PARTICIPACIÓN CIUDADANA EN LA ADMINISTRACIÓN DE JUSTICIA.}

La participación de los ciudadanos es una parte fundamental de la democracia y, generalmente, la consideramos en su vertiente política del voto o la consulta ciudadana. Sin embargo, estas no son las únicas formas. Las instituciones del Estado o, desde la perspectiva de la división del poder público, cada uno de los poderes del Estado y los órganos constitucionales autónomos, también involucran en sus actividades a la ciudadanía. (Reyes, 2019). 
Seguidamente, consideramos imprescindible desarrollar los fundamentos por los cuales la ciudadanía se encuentra legitimada de ser partícipe en asuntos del Estado, en el presente caso, de la administración de justicia.

Para ello, tenemos que empezar reseñando grosso modo el origen del Estado. Y es que a la luz de lo señalado por Jean-Jacques Rousseau, en su capital obra: "El Contrato Social". Es así, que en antiguo los ciudadanos se empezaron a organizar para designar responsables que se encargasen de los asuntos básicos de interés de todos. Por ejemplo: seguridad, salud, educación, entre otros.

Sin embargo, en vista del crecimiento que iba experimentando las poblaciones, es que decidieron crear a un ente abstracto, de alcance nacional. El mismo se encargaría de velar por las necesidades básicas de la población. Esto es, sumados a los señalados, están los servicios públicos, por citar alguno. El cual recibió por denominación: Estado.

Entonces, en vista que el Estado fue exclusivamente creado para favorecer a la población, resulta ser una obligación el asumir una postura responsable y muy correcta cuando nos encontramos laborando (realizando una gestión pública) en alguna entidad del Estado.

Seguidamente, desarrollar un tema al que consideramos de primerísimo orden, el cual se encuentra indisolublemente ligado al manejo público, a la responsabilidad social empresarial, a la gerencia social, así como, a la vida política, democrática justas, saludables y edificantes que se merece toda persona: es decir, nos estamos refiriendo al valor público (tema pilar, como propio de la quintaesencia de la administración pública).

¿Constituye una obligación para quienes están a cargo de gestión pública, porque los mismos laboran con fondos públicos, los cuales le pertenecen a la población y por ende deben estar orientados hacia ella en general y específicamente a los sectores más deprimidos y no a otros fines, menos aún, cuando los referidos?, otros fines?, postergan y desnaturalizan la finalidad que abraza la función pública (sea derivada generada vía elección popular o no). Así, el valor público, busca de forma comprometida, un sistema que promueva un desarrollo eficaz, eficiente, equitativo y sostenible. Bajo esta perspectiva, se busca la creación de valor público por medio de una gestión estatal, la que tiene que contribuir significativamente a cuatro fines o principios fundamentales: i) Reducción de la desigualdad, ii) Reducción de la pobreza, iii) Fortalecimiento de estados democráticos, iv) Fortalecimiento de la ciudadanía. 
Jorge Isaac Torres Manrique

El valor público no es un producto ni un resultado, sino, más bien un proceso complejo, cuyas etapas posteriores de desarrollo solo pueden acometerse en la medida en que se han cumplido con éxito aquellas de carácter preliminar. Ergo, el valor de marras genera una mejor reputación colectiva, que deriva en la colaboración mutua entre la empresa, los agentes de mercado y el Estado, que permite un beneficio y un respeto recíprocos sobre la base de comprender, y distinguir, los objetivos y roles que cada uno cumple: confluyendo en un beneficio y superación colectiva.

Luego tenemos que, en vista que no solamente la ciudadanía crea al Estado, sino que, además, solventa su funcionamiento basilarmente con los impuestos que abona, la misma se encuentra legitimada para poder hacer valer sus derechos a la transparencia y acceso a la información pública, en tanto que precisa saber cómo se gasta y se invierte los mismos. En ese sentido, la participación de la ciudadanía en la administración de justiciar se encuentra plenamente legitimada. Así, el amis curiae, resulta ser correspondiente a ello.

La intervención en calidad de amicus curiae no es exclusiva de los particulares, sino también pueden ser incluidas como amicus curiae las entidades del Estado, siempre y cuando puedan brindar elementos técnicos para para resolución de conflictos: Sin embargo, como ya hemos analizado en la jurisprudencia vinculante del Tribunal Constitucional, los informes y solicitudes para ser considerados como amicus curiae son presentados por particulares y en menor grupo por entidades públicas. (Sandoval, 2018).

Empero, resulta imprescindible reflexionar acerca de: ¿Cómo puede acreditarse el interés público en una determinada causa? O en su defecto ¿Qué podemos entender por interés público?, debemos analizar adecuadamente las sentencias del Tribunal Constitucional peruano, puesto que el interés público variará conforme la realidad social siga siendo tan cambiante o la necesidad peruana varíe drásticamente como hasta la fecha. (Sandoval, 2018).

Seguidamente corresponde ocuparse de la importancia, aceptación y consideración que la judicatura le otorga al amicus curiae.

En ese sentido, tenemos una ficción de participación ciudadana. Permitimos participar, pero para que se saquen las ganas, no vamos a tomar en cuenta lo que digan ¡qué quede claro! Si bien como digo tiene cara de ficción, es positivo, es necesario y el desafío es seguir trabajando en esta línea; porque en definitiva ¿dónde tiene que producirse el debate público? Dirán, en el Congreso. Bueno no hay mecanismos. Entonces, se insta a el debate democrático se de en otro escenario, el poder judicial. Mientras tanto, es súper interesante la forma de suplir la deliberación pública a través de opiniones escritas. Opiniones que 
representan argumentaciones jurídicas relevantes para un caso, pero bien fundamentos que quedan silenciados. (S/a., 2015).

Por otro lado, respecto de la oportunidad o momento de presentación del amicus curiae, es de verse que el Fund. 16., de la Corte Interamericana de Derechos Humanos, Caso Kimel vs. Argentina, señala:

"En lo referente a la supuesta extemporaneidad del escrito de la Asociación por los Derechos Civiles, el Tribunal observa que los amici curiae son presentaciones de terceros ajenos a la disputa que aportan a la Corte argumentos u opiniones que pueden servir como elementos de juicio relativos a aspectos de derecho que se ventilan ante la misma. En este sentido, pueden ser presentados en cualquier momento antes de la deliberación de la sentencia correspondiente. Además, conforme a la práctica de esta Corte, los amici curiae pueden incluso referirse a cuestiones relacionadas con el cumplimiento mismo de la sentencia. Por otra parte, la Corte resalta que los asuntos que son de su conocimiento poseen una trascendencia o interés general que justifica la mayor deliberación posible de argumentos públicamente ponderados, razón por la cual los amici curiae tienen un importante valor para el fortalecimiento del Sistema Interamericano de Derechos Humanos, a través de reflexiones aportadas por miembros de la sociedad, que contribuyen al debate y amplían los elementos de juicio con que cuenta la Corte. En consecuencia, el Tribunal rechaza la objeción de extemporaneidad presentada por el Estado (...)".

Por su parte, es de verse que una temática importante resulta ser el gobierno abierto. Así, debemos entender por gobierno abierto es un modelo, un paradigma de gestión gubernamental, un modo de organizar el sistema de gobierno que permite realizar y consolidar el sistema republicano y la democracia participativa en la práctica, mediante la redefinición de la interacción entre el Estado y la ciudadanía, donde priman la transparencia, la rendición de cuentas, la colaboración y la participación de la sociedad, de modo de reequilibrar la ecuación del poder, objetivo buscado, al menos, desde la consolidación del constitucionalismo moderno. Una ecuación de poder que se sostiene sobre una premisa básica: el centro de toda construcción de lo público debe ser la persona humana, titular, dueño y responsable de la construcción colectiva a la que llamamos Estado. (Sá, 2018).

En ese sentido, respecto de la relación entre el gobierno y el amicus curiae, amerita traer a colación que (Sánchez, 2017):

i) En primer lugar, que los elementos de un gobierno abierto son: i) Transparencia, ii) Participación, iii) Colaboración, y iv) Datos abiertos. 
Jorge Isaac Torres Manrique

ii) En segundo término, que la transparencia en el poder judicial, en el marco de una justicia abierta, comporta basilarmente: i) Transparencia y acceso a la información judicial, ii) Participación en el sistema de justiciar, iii) Colaboración entre los poderes judiciales y la sociedad civil, y iv) Datos abiertos.

iii) Finalmente, en tercer lugar, dejar constancia que la participación en el sistema de justicia: el concepto de partipatory justicie, un modelo de solución a las problemáticas donde las partes participan activamente en la búsqueda de soluciones. Este modelo incluye métodos dirigidos a reforzar la participación, el consenso y la prevención de conflictos. Se considera menos costoso, más rápido e igual de eficaz que el modelo tradicional. Dentro de este grupo, se incluyen instituciones del derecho civil, como la mediación, la conciliación y el arbitraje. También la herramienta del amicus curiae, a través de la cual el poder judicial solicita a personas e instituciones con trayectoria en un tema su opinión frente a un caso en particular.

Huelga señalar, que aumentan las probabilidades de una decisión judicial correcta cuando los amicus curiae presentan argumentaciones jurídicas o científicas, o puntos de vista que el juez no ha tenido en cuenta. Así, ahora el tribunal deberá hacerse cargo de esos argumentos, aumentando la calidad del debate y el control de las aseveraciones vertidas en juicio. (Hidalgo, 2017).

\section{UNA MIRADA DESDE LOS DERECHOS FUNDAMENTALES.}

El "amicus curiae" tiene rol de suma importancia a la consumación del debido proceso legal en lo aspecto que concierne al derecho de influencia el juzgador, ya que es el sujeto del proceso. Y tal derecho de influenciar por supuesto llevará el juzgador a mejor desempeñar su rol jurisdiccional, fundamentando con corrección los juzgados, llevándose en cuenta el refuerzo recibido del amigo de la Corte con reconocida capacidad de fornecer elementos al magistrado. (Costa de Santana, 2014).

El amicus curiae garantiza el acceso a la justicia, pues este instrumento es una vía subsidiaria de la legitimación activa para ejercer una acción, de modo que quien no cumpla con los requisitos de admisibilidad de la acción, pueda participar como amicus. Esto demuestra que el amicus curiae es un instrumento legal moderno que se ajusta e integra en un sistema jurídico basado en la concepción de un Estado Constitucional Democrático de Derecho. (Hidalgo, 2017).

En la Comisión y la Corte Interamericana de Derecho Humanos el amicus se ha empleado en importantes casos litigiosos (v.g. Caso Consuelo Benavides Cevallos, Ecuador) y en la totalidad de las opiniones consultivas (OC-7/86 sobre derecho de rectificación o respuesta; 
OC-16/99 sobre derecho a la información sobre asistencia consular en el marco de las garantías del debido proceso, entre otras). (Borda, s/a).

El amicus está llamado a cumplir un papel relevante en la medida en que puede proporcionar a los magistrados actualizadas pautas atinentes a la interpretación y la aplicación de los tratados internacionales sobre derechos humanos, por parte de — v. g.los aludidos órganos del sistema protectorio interamericano, espectro en el que no cabe soslayar que los documentos internacionales recipiendarios de jerarquía constitucional por conducto de la reforma de 1994 (y los que se añadan en el futuro) valen tanto como la propia Carta Magna y representan (al igual que el texto y el espíritu de la Constitución formal) parámetros para el contralor de constitucionalidad de la normativa legal e infra legal. (Borda, s/a).

Queda pues, de manera contundentemente acreditada la relación existente entre el amici curiae y los derechos fundamentales, ya sea en el proceso, en la jurisdicción interna estatal, así como, en la jurisdicción internacional. Y lo propio, respecto de la no vulneración de derecho fundamental alguno por parte del mismo.

No obstante, resulta de menester determinar los irrestrictos derechos fundamentales invocados en iter de la participación del amicus. Así, sostenemos que los mismos son: i) El derecho fundamental a influir en el juicio, ii) Debido proceso, iii) Legitimidad funcional de la judicatura, iv) Principio de legalidad de las actuaciones de los poderes públicos, vi) Tutela jurisdiccional, vii) Independencia judicial, viii) Ponderación judicial, ix) Razonabilidad, x) Igualdad, xi) Democratización del proceso y debate, xii) Participación ciudadana, entre otros.

\section{Puntos pendientes del AMICI CURIAE.}

5.1. Proscripción del mero protagonismo. Asumir en serio la participación de la ciudadana en la administración de justicia, pasa por el compromiso de participar en los casos más relevantes, pero, se entiende que es desde la más acuciosa y especializada exposición. Ello comporta dejar de lado todo tipo de sensualidad del mero figuretismo como acaparamiento de la atención, incluso de la prensa.

En ese sentido, se debe tener en cuenta que esta posibilidad debe ser ejercida de manera inteligente, es decir, la opinión debe ser trascedente para la resolución del conflicto jurídico. Lo ideal es que los amici curiae expongan argumentos que las partes no han querido traer al proceso por decisiones de estrategia procesal o que hagan notar al juez o tribunal que hay elementos de juicio que no están teniendo en consideración. De otra forma, no sería posible sustentar la existencia del amicus curiae, quien solo dilataría el proceso e 
Jorge Isaac Torres Manrique

intervendría ilegítimamente en una disputa judicial respecto de la cual no se encuentra legitimado para ejercer una acción apta para obtener tutela judicial. (Hidalgo, 2017).

5.2. Compromiso del tribunal. Para que la apertura efectivamente se manifieste (como parte del gobierno abierto en sede judicial), es preciso que el tribunal (ora individual, ora colegiado), no solamente autorice la participación de los amici curiae, sino que, además, asuma el compromiso de acoger los argumentos que en su caso requieran ser atendidos, por la contundencia de argumentación especializada.

Si bien es cierto, que lo sustentado por el amigo del tribunal no vincula al mismo, no significa el mismo deba hacer oídos sordos a su alocución y aporte, más aún laminarmente.

5.3. Fomento para su mayor participación. Basilarmente se aprecia la presencia del amici curiae en sede judicial como del Tribunal Constitucional y en los casos emblemáticos. En ese sentido, corresponde fomentar y hacer más atractiva la participación del amicus, debido a que las correspondientes decisiones judiciales afectarán en mayor o menor medida a los derechos fundamentales de la población.

Además, resulta muy positivo para efectos que las minorías puedan verse no solamente representadas, sino, además, salvaguardadas en contrapeso de las mayorías, vía la presentación del amicus. Ello genera y fortalece a su vez la legitimidad de la judicatura muchas veces esquiva. Entonces, la necesidad de regulación normativa especializada como detallada, deviene en imprescindible, urgente, insoslayable.

5.4. En sede administrativa. A pesar que el amicus curiae se encuentra presente en sede judicial y arbitral, aun no es percibirle en predios administrativos, en donde la materia comporte el interés público. Y es que, consideramos que resulta perfectamente viable que, en los casos de tribunales administrativos, el irrestricto derecho fundamental a la consulta previa, libre e informada de los pueblos indígenas, puede tener en la figura del amicus curiae, un gran aliado.

5.5. Regulación legal y constitucional. Su participación deberá estar debida como específicamente establecida, tanto en sede legal, como constitucional.

En ese sentido, además, tomando como premisa que los derechos fundamentales ambientales, corresponden a todos en general y a nadie en particular, reviste de alta importancia y urgencia la regulación normativa para la intervención normativa del amicus en materia ambiental. 
Un sistema jurídico que ostenta un pleno reconocimiento normativa del amicus curiae es Chile, por ejemplo. Hablamos de reconocimiento normativo porque, como veremos luego, el amicus curiae se encuentra reconocido en fuentes formales de distinta jerarquía. Así, es posible hablar de un reconocimiento constitucional, supra legal, legal y reglamentario. (Hidalgo, 2017).

Respecto de la regulación normativa pendiente del amicus curiae, es de considerar numerosos asuntos por estudiar, analizar, desarrollar. Verbi gratia (Bazán, s/a):

i) Discernir si su intervención solo podrá ser solicitada por los amicus curiae, las partes o si también el tribunal recibirá atribución para requerir motu proprio dicha participación.

ii) Si las partes pueden o no oponerse a que los asistentes oficiosos actúen en el proceso.

iii) Si cabe corre traslado del pedido de éstos para intervenir en la causa y si, ante la oposición de los litigantes podría igualmente el tribunal concede a los amici habilitación para ingresar al proceso.

iv) Sí, no obstante, la conformidad expresa o tácita de las partes, podría de todos modos el tribunal rechazar la presentación de los asistentes oficiosos.

v) $\mathrm{Si}$, admitida la participación de éstos, les estará vedada siempre y en todos los casos la posibilidad de plantear recursos; o si, no aceptada su actuación, podrán recurrir esa desestimación inicial.

vi) Dilucidar si la actuación de los amici puede darse en cualquier proceso y en cualquier instancia o si, por el contrario, estará reservada a determinadas causas y/o ante ciertas instancias específicas, v. g., la CSJN, la Cámara Nacional de Casación Penal y las Cámaras Nacionales y Federales de Apelación; o sólo ante alguno de tales órganos jurisdiccionales.

vii) Si la presentación de amicus curiae debería quedar limitada sólo a personas u organismos de reconocida especialización y/o experiencia con relación al asunto en debate o si la participación debería ser, al menos a priori, amplia o indiscriminada.

viii) Si los escritos sólo deberían versar sobre cuestiones jurídicas o también podrían introducirse en aspectos fácticos de la causa.

ix) Explicitar si el memorial deberá cumplimentar ciertos requisitos formales; en su caso, cuáles y en qué instrumento normativo estarán contenidas tales pautas a observar.

x) Esclarecer si un amicus sólo puede presentarse en una de las instancias judiciales del proceso y no repetir en las superiores o si, por el contrario, estaría habilitado para hacerlo y, asimismo, establecer si el mismo presentante podría incorporar - 
Jorge Isaac Torres Manrique

en casos excepcionales y por hechos o circunstancias sobrevinientes que lo justificaren - más de un memorial por instancia; y

xi) Determinar si le serán oponibles los efectos de la cosa juzgada de la sentencia que resuelve la causa en la que comparece.

5.6. Capacitación y especialización. La temática de la debida capacitación y especialización de la totalidad de los actores de la administración de justicia, deviene en imprescindible como insoslayable (se constituye en un lugar común para los sistemas jurídicos). Empero, la misma debe entenderse de manera vertical de arriba hacia abajo y no desde abajo hasta antes de los gerentes y directores.

Al respecto, no se debe perder de vista que la misma no solo debe estar encabezada por verdaderos especialistas en la correspondiente materia en sede jurídica, sino además, que se tiene que considerar también, la administración. Esto es, una capacitación más allá del Derecho, interdisciplinaria.

Así también, el propósito de la capacitación no puede agotarse en el mero hecho de ser tal, sino más bien, en la asimilación, concientización y efectiva como eficaz puesta en práctica. De otro modo, no tendría razón de tal si es que es asumida únicamente para considerarla per se, como logro de un objetivo de gestión y la certificación correspondiente.

5.7. Proscripción de la egolatría y mesianismo. Resulta sumamente preocupante la eventual consabida ligereza con que resultan ser asumidas las modificaciones o propuestas legislativas, a la luz de las correspondientes comisiones de reforma.

Ello ocurre cuando en principio, no necesariamente son convocados para ello a los verdaderos especialistas. Luego, que las propuestas y modificaciones terminan siendo producto de una coyuntura y no de una real necesidad legislativa. Lo referido aterriza en que antes de la creación de una comisión de reforma, increíblemente ocurre que las respectivas modificaciones y propuestas, simplemente no existían.

Mención aparte, merece referir a lo que el jurista peruano Mario Castillo Freyre señala como "Tentaciones Académicas". Esto es, que entre no pocos miembros de las comisiones de reforma observan el principio ("yo no opongo a tus propuestas de artículos para la ley y tú no te opones a las mías"). Luego, acuerdan que finalmente que vaya el paquete completo sin mayor debate y análisis, en atención a que en el Congreso de la República el legislador hará las observaciones y enmiendas correspondientes. Lo que ciertamente no siempre ocurre. Como consecuencia, es que puede apreciar leyes aprobadas en las que su articulado no presenta la obligada sistematización interna y externa, y donde existen algunos en los que el texto presenta contenido repetido, incompleto, contradictorio. 
Además, no se puede dejar de apostrofar el que no pocos dadores de una norma legal, resultan más preocupados por la permanencia de vigencia de una ley nociva o errada por contener una propuesta de su persona, en vista que no pueden concebir que su nombre deje de estar presente en la dación o propuesta de la misma. Entonces, se oponen por todos los medios posibles a la eventual modificación de la supuesta iluminada ley, que ellos fueron autores, gestores o promotores. Es el típico caso de aquellos que se consideran predestinados a trascender sin mayor o ningún mérito o fundamentación suficiente.

5.8. Sintonía con el Estado de Justicia. Dejamos expresa constancia, que ciertamente el Derecho actual no puede lograr satisfactoriamente sus fines, en tanto que el mismo se ajusta a unimismancia de sistema jurídico imperante, esto es, el Estado Constitucional de Derecho, el mismo que no ser equiparable ni sinónimo de justicia. Esto es, que su filosofía resulta constitucional, pero injusta. (Torres, 2018). Fundamentamos de referido en los siguientes términos:

En primer término, a la Justicia Legal se le suele denominar de dicha manera, en razón a su abrace de conformidad a lo estipulado en la norma legal respectiva, esto es, cuando en sede judicial o administrativa se decide ajustándose a lo contemplado exclusivamente en la ley de la materia, para el caso concreto. O que también se invoque el otorgamiento de un derecho establecido en el texto expreso de la ley.

Seguidamente, se tiene en la Justicia Constitucional una definición que observa estrictamente los postulados de la Constitución Política. Entonces, queda claro que este tipo de justicia no es equiparable a la justicia legal.

A continuación, la Justicia Convencional es a la que se arriba tomando como premisa lo juridizado en la Convención Americana de Derechos Humanos: Su alcance o cercanía a la justeza es superior a la que ofrecen la justicia legal y la constitucional.

Luego, es de verse el significado de la Justicia Restaurativa se encuentra relacionado al espíritu que la restauración contempla para los sujetos ofendidos o agraviados. Si bien restaura a la totalidad de ofendidos o perjudicados, no necesariamente se le otorga lo que le corresponde a la víctima, sino, lo que subjetivamente considere la misma para quedar o saberse restaurada. No pocas veces el alto contenido emocional, hace que lo que precise el ofendido, sea basilarmente el otorgamiento de las sinceras como sentidas disculpas y satisfacciones del ofensor, con cargo de no volver a incurrir en la correspondiente ofensa u agravio. Con ello, la víctima se vería en cierta forma, por satisfecha. Entonces, la justicia restaurativa arriba a un peldaño más arriba que la justicia legal, constitucional y convencional. 
Jorge Isaac Torres Manrique

Finalmente, tenemos a la Justicia, a la justicia propiamente dicha, la única equiparable a la legitimidad, a la justeza. Este tipo de justicia, es a la que se refiere con el dar a cada quien lo que le corresponde. Justiniano señaló al respecto: "La Justicia es la constante y perpetua voluntad de dar a cada uno su derecho". Así, la justicia no puede ser equiparable a la justicia restaurativa, ya que, a diferencia de esta última, la carga o necesidad emocional no se plasma, debido a que, si el ofensor la robó al ofendido diez cabezas de ganado, pues, será justo o de justicia, que el ofendido reciba del ofensor el número completo y calidad (características) de lo robado y en extremo alguno, unas disculpas que puedan hacer las veces de bálsamo reductor del número y naturaleza de lo robado. Que no se nos malentienda, ya que no estamos en contra, demonizamos, rebajamos o desmerecemos a la justicia restaurativa, solo la comparamos con la justicia. Entonces, queda demostrado que la justicia, no es igual y es a la vez muy superior a la justicia legal, constitucional, convencional y restaurativa.

No obstante, es preciso dejar constancia que en strictu sensu, la única justicia válidamente existente, es la justicia propiamente dicha o justicia verdadera. Y es que, no se trata de erradamente pretender otorgar mayor significancia o supremacía utilizando nombres rimbombantes para "crear" diversos tipos de justicia, cuando la justicia es una sola, dicho de otro modo, la última de las analizadas.

A propósito, cabe hacer mención a la marcada gradualidad ascendente entre: legalidad, constitucionalidad, convencionalidad, restauratividad y justicia.

Para concluir y en mérito a lo desarrollado, colegimos que a lo que debemos aspirar como único norte inquebrantable e innegociable; es a la mención, defensa y plasmación de la justicia propiamente dicha, esto es, a la legitimidad, a la justeza, es decir, a la justicia verdadera.

No obstante, lo desarrollado, sostenemos que no necesariamente tenemos que esperar a que algún día se encuentre el ansiado Estado de Justicia, puesto que desde ya podríamos abrazarlo premuniéndonos del principio de legitimidad.

\section{A MODO DE COLOFÓN.}

Los puntos desarrollados como agenda pendiente, obstaculizan la efectiva como plena participación del amicus curiae en gran parte de los sistemas jurídicos del orbe. En ese sentido, sugerimos se considere atender de manera urgente los diversos puntos expuestos. La capacitación y concientización en la temática de efectiva aplicación del amicus y de los puntos de agenda mencionados, constituyen en señero importante para lograr abrazar los mencionados puntos pendientes de atención y convertirlos en logros cumplidos. 
El principal desafío del amicus curiae, es lograr su plena aplicabilidad a la vez de observar estrictamente los derechos fundamentales de los diversos actores del mismo, así como, lo propio de los principios y derechos que comporta el sistema jurídico imperante y la interdisciplinariedad. Esta última, en sede de especialización. Esto es, aterrizar en la naturaleza de su quintaesencia y dación como tercero coadyuvante.

\section{REFERENCIAS BIBLIOGRÁFICAS.}

Baquerizo, J. (2006). El amicus curiae: Una importante institución para la razonabilidad de las decisiones judiciales complejas. Revista Jurídica, Facultad de Jurisprudencia. Universidad Católica de Santiago de Guayaquil. Edición No. 21, p.p. 1-28.

Bauer, F. (2016). El amicus curiae en la jurisdicción constitucional española. Revista Española de Derecho Constitucional, No. 108, p.p. 101-199. DOI: https://doi.org/10.18042/cepc/redc.108.06

Bazán, V. (2014). Amicus curiae, justicia constitucional y fortalecimiento cualitativo del debate jurisdiccional. Revista Derecho del Estado. No. 33, p.p. 3-34.

Bazán, V. (2004) Amicus curiae, transparencia del debate judicial y debido proceso. En Anuario de Derecho Constitucional Latinoamericana, Tomo I. México: UNAM. p.p. 251280

Borda, G. (2011). El Amicus Curiae. Revista SIGNOS Universitarios, Vol. 30, No. 46. Universidad del Salvador.

Caro Mejía, K. (2018). Hermenéutica judicial para la protección de los segundos ocupantes en el proceso de restitución y formalización de tierras. Revista Jurídica Mario Alario D'Filippo, Vol. 10, Número 19: 250-270. DOI: https://doi.org/10.32997/2256-2796-vol.10num.19-2018-2142

Castañeda, F. (20 de enero de 2010). El “amicus curiae” ¿qué es y para qué sirve? Blog de la Defensoría del Pueblo. https://www.defensoria.gob.pe/blog/\%C2\%BFque-es-y-paraque-sirve-el-\%E2\%80\%9Camicus-curiae\%E2\%80\%9D/

Cesario, S. Guía de Herramientas de Participación Ciudadana para Docentes. Disponible en: http://www.gestionsocial.org/archivos/00000854/Cesario.pdf, Buenos Aires, s/a.

Costa, L. (2014). "Amicus Curiae": El derecho a influir en el juicio (das Recht auf Berücksichtigung) como proyección del debido proceso legal. Mgalhas Latinoamérica. 
Jorge Isaac Torres Manrique

https://la.migalhas.com/Articulos/147,MI210327,41046Amicus+Curiae+El+derecho+a+i nfluir+en+el+juicio+das+Recht+auf

González, M. y Sotelo, A. (2019) Amicus curiae: un vínculo entre ciudadanía y justicia. Laboratorio Nacional de Diversidades. P.p. 1-42.

Herrero, A. (2008) Poder Judicial, transparencia y participación ciudadana: reformas recientes en Argentina. Revista Iberoamericana. Vol. 8, No. 31, p.p. 175-179. DOI: http://dx.doi.org/10.18441/ibam.8.2008.31.175-179

Hidalgo, R. (2017). Fines y funciones del amicus curiae: Perspectivas para Chile. Pontificia Universidad Católica de Valparaíso.

Kalach Torres, Gina María (2016). Las comisiones de la verdad en Colombia. Revista Jurídica Mario Alario D'Filippo, Vol. 8, número 16: 106-124. DOI: https://doi.org/10.32997/2256-2796-vol.8-num.16-2016-1534

Martin, J. (2015). El amicus curiae como herramienta de participación de la sociedad civil en las decisiones judiciales trascendentes. El caso de la iglesia adventista del séptimo día. Revista de Estudos e Pesquisas Avançadas do Terceiro Setor. Vol. 2. DOI: 10.18839/2359$\underline{5299 / \text { repats.v2n2p1-35 }}$

Mendoza, R. (2019). El Amicus Curiae como instrumento de participación ciudadana para vigilar la actuación del Poder Judicial de la Federación. Pérez Góngora \& Asociados. https://perezgongora.com/amicus-curiae-instrumento-de-participacion-ciudadana/

Sandoval, S. (2018). Análisis jurídico de la participación de los amicus curiae en la actividad jurisdiccional peruana, 2010-2017. Repositorio Universidad Nacional de San Agustín de Arequipa. http://repositorio.unsa.edu.pe/handle/UNSA/7088

Serie de documentos defensoriales. Adjuntía (e) en Asuntos Constitucionales de la Defensoría del Pueblo. (2009). El amicus curiae: ¿qué es y para qué sirve? Jurisprudencia y labor de la Defensoría del Pueblo. No. 8, p.p. 1-102. https://www.corteidh.or.cr/tablas/26654.pdf.

Reyes, J. (2019). Hacia una ciudanización de la administración de justicia. La experiencia del tribunal superior de justicia de Oaxaca. Blog EQUIS. https://equis.org.mx/hacia-unaciudadanizacion-de-la-administracion-de-justicia/ 
Mundiario, Primer Periódico Global de Análisis y Opinión (26 de octubre de 2015). Posibilidades de participación ciudadana en los casos judiciales. Mundidiario. https://www.mundiario.com/articulo/sociedad/posibilidades-participacion-ciudadanacasos-judiciales/20151026230301048466.html

Sá, G. (2018). Sistema de justicia y gobierno abierto ¿Es viable una justicia abierta? Cuaderno de Derecho Judicial, No. 28. https://www.austral.edu.ar/derecho/wpcontent/uploads/2019/03/cuaderno-28-gustavo-sa-zeichen.x12321.pdf,

Sánchez, J. (2017). Transparentando los poderes públicos: Gobierno abierto, parlamento abierto y justicia abierta. Revista Venezolana de Gerencia, Vol. 23, No. 81, Universidad del Zulia.

Torres, J. (2018). Justicia legal, justicia constitucional, justicia convencional, justicia restaurativa, justicia. ¿Son sinónimos? El terno. https://www.elterno.com/colaboradores/Jorge-Isaac/Justicia-legal-justicia-constitucional.html

Viguri Perea, A. y Chiara Marullo, M. (2016) El derecho a un medio ambiente sano y la encrucijada de los alimentos transgénicos. Revista Jurídica Mario Alario D'Filippo, Vol. 8, Núm. 15: 100-111. DOI: https://doi.org/10.32997/2256-2796-vol.8-num.15-2016-1526 